\title{
LDL heterogeneity: implications for atherogenicity in insulin resistance and NIDDM
}

\section{D.J.B etteridge}

Department of Medicine, The Middlesex Hospital, London, UK
It is low density lipoprotein (LDL), the major cholesterol-rich lipoprotein, which accounts for the link between increasing plasma cholesterol and coronary heart disease risk. Although once considered to be homogeneous it has become clear that LDL comprises a spectrum of particles.

\section{LD L subclasses}

Studies employing density gradient ultracentrifugation and gel electrophoresis have demonstrated that the LDL density range is comprised of a number of discrete subclasses which vary in size, density and lipid content [1] (Fig.1). As the density of the LDL species increases, particle diameter, flotation rate and relative content of total and polar lipids all decrease. LDL-II is the most abundant subspecies in healthy individuals. Women tend to have proportionally more LDL-I than men while men have proportionally more LDL-III.

\section{D L subclasses and coronary heart disease}

Non-denaturing, gradient-gel electrophoresis which determines particle size is the most commonly used technique for studying LDL heterogeneity and is suitable for large-scale clinical application. Two distinct LDL subclasses have been defined; pattern A, major peak diameter over $25.5 \mathrm{~nm}$, and pattern $\mathrm{B}$,

Corresponding author: Prof. D.J.Betteridge, Department of Medicine, University College London, The Middlesex Hospital, Mortimer Street, London WIN 8AA, UK

A bbreviations: LDL, Low density lipoproteins; HDL, high density lipoprotein; VLDL, very low density lipoprotein; CETP, cholesterol ester transfer protein; Sf, Svedberg flotation units; NIDDM, non-insulin-dependent diabetes mellitus. major peak diameter under $25.5 \mathrm{~nm} \mathrm{[2].} \mathrm{Using} \mathrm{this}$ technique Austin and colleagues [3] demonstrated a preponderance of LDL pattern B in myocardial infarction survivors compared to healthy control subjects. This was associated with a threefold risk of infarction independent of age, gender and body weight but dependent on plasma triglyceride and high density lipoprotein (HDL) cholesterol [3]. The term atherogenic lipoprotein profile was coined to describe the clustering of moderate hypertriglyceridaemia $(>1.7 \mathrm{mmol} / \mathrm{l})$ circulating as large VLDL, reduced HDL cholesterol and a predominance of small dense LDL [4]. Similar findings have been described by others who have measured LDL particle size on gels and separated LDL subclasses by ultracentrifugation [5-9]. In atheroma regression studies small dense LDL has been shown to be related to reduced coronary artery diameter [10].

\section{M etabolic determinants of $L D L$ subclasses}

Many factors have been shown to influence LDL subclass distribution including cholesterol ester transfer protein (CETP) activity, hepatic lipase activity, apoprotein $\mathrm{E}$ phenotype, gender, body weight, exercise and genetics. However, the presence of hypertriglyceridaemia appears to be a major determinant [1113]. Plasma triglyceride is negatively correlated with LDL size and approximately $70 \%$ of the variability of LDL distribution can be explained by triglyceride and HDL cholesterol variations [14].

An attractive hypothesis to explain this relationship is the stimulation of neutral lipid exchange via CETP by the concentration of triglyceride-rich lipoproteins. Triglyceride transfers to LDL in exchange for cholesterol ester and the triglyceride-enriched particles become a substrate for hepatic lipase resulting in protein-rich, lipid-poor particles with a density 


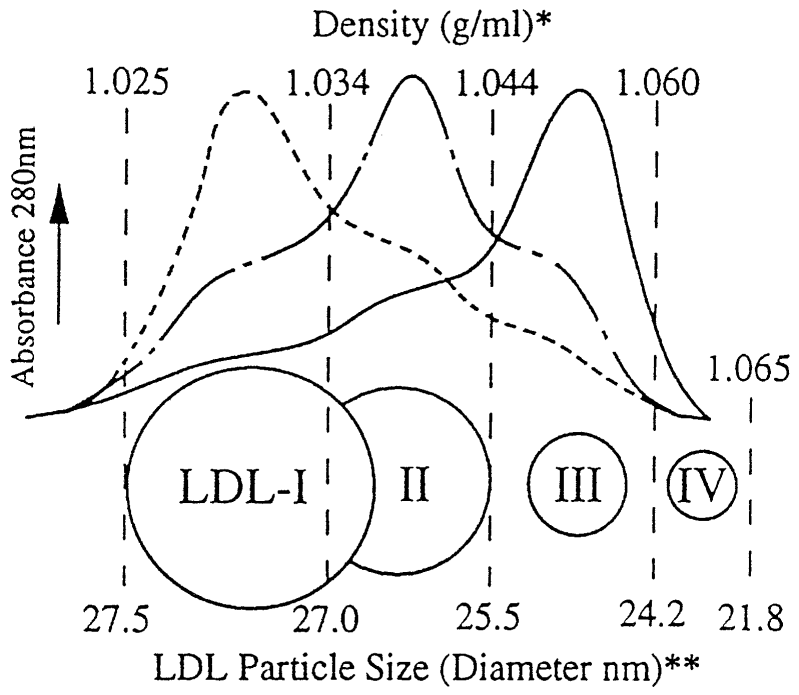

Fig. 1. Distribution of human plasma LDL subclass density and particle size. *LDL: subclass density profiles obtained by density gradient ultracentrifugation and representative of a typical normal, healthy female $(---)$, male $(-\bullet-)$ and CAD pa-

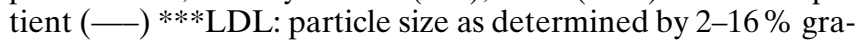
dient gel electrophoresis. Reproduced from reference [33]

resembling LDL-III. Kinetic studies suggest that $\mathrm{VLDL}_{1}$ (Svedberg flotation units (Sf) 60-400) particles, which are present in hypertriglyceridaemia, give rise to LDL-III particles whereas the smaller VLDL 2 (Sf 20-60) found in normal and hypercholesterolaemic individuals gives rise to LDL-II particles. Enhanced postprandial lipaemia is probably also an important determinant of the production of small dense LDL [15].

\section{LD L subclasses and atherogenicity}

Whether small dense LDL are directly atherogenic remains to be fully proven. However, the literature points to several possible mechanisms whereby small dense LDL may be atherogenic including increased infiltration into the arterial wall [16]. Increased sequestration due to enhanced binding to arterial proteoglycans $[17,18]$ possibly related to conformational changes in apoprotein B [19] and reduced carbohydrate and sialic acid content [20] has been reported. Increased susceptibility to oxidation has also been reported for small dense LDL [21].

\section{$L D L$ subclass distribution in insulin resistance and non-insulin-dependent diabetes mellitus (NID D M)}

Hypertriglyceridaemia often associated with low HDL cholesterol concentration is a common finding in NIDDM and often persists despite best efforts at glycaemic control. Several studies have pointed to the strong relationship between triglycerides and coronary heart disease risk and this relationship may be explained in part by abnormal postprandial lipaemia, the accumulation of remnant particles and a shift in the LDL distribution towards small dense particles [22].

In a group of poorly controlled, obese NIDDM patients with hypertriglyceridaemia a reduction in intermediate density LDL and a concomitant increase in small, dense LDL was observed [23]. Similarly, morbidly obese (BMI $>40 \mathrm{~kg} / \mathrm{m}^{2}$ ) and hypertriglyceridaemic NIDDM females were shown to have a preponderance of small, dense LDL particles [24]. In a further study there was a greater impact of diabetes on LDL size in women than in men [25]. LDL size and peak density in mildly hyperlipidaemic patients correlated with insulin resistance [26]. Similar results have been obtained in studies which separated LDL subclasses by ultracentrifugation; insulin resistance correlated inversely with LDL-I concentrations and positively with LDL-III and 32-33 split proinsulin correlated with LDL-III [27]. Furthermore, in non-diabetic individuals subjects with a preponderance of small dense particles have been demonstrated to be more insulin resistant $[28,29]$ and small dense LDL can be considered to be part of the insulin resistance syndrome [30].

Hypertriglyceridaemia has a major impact on LDL concentrations in the non-diabetic population [31] and this is also the case in NIDDM [27, 32]. In the fasting state multivariate analysis showed that fasting triglyceride concentrations, HDL cholesterol and hepatic lipase activity were the most important determinants of LDL-III $\left(R^{2}=67 \%\right)$. Postprandially, chylomicron remnant clearance, hepatic lipase activity and insulin resistance were the major determinants of LDL-III $\left(\mathrm{R}^{2}=61 \%\right)$ [27].

The mechanisms explaining the link between insulin resistance and LDL heterogeneity remain to be fully elucidated. However, it is known that insulin resistance is associated with increased non-esterified fatty acid flux to the liver, increased hepatic output of large VLDL which is not suppressed postprandially, increased postprandial lipaemia, increased activity of hepatic lipase and increased CETP activity. All these factors would tend to favour the formation of small dense LDL-III particles.

\section{References}

1. Krauss RM, Burke DJ (1982) Identification of multiple subclasses of plasma low density lipoproteins in normal humans. J Lipid Res 23: 97-104

2. Austin MA, Krauss RM (1986) Genetic control of low density lipoprotein subclasses. Lancet 2: 592-595

3. Austin MA, Breslow JL, Hennekens CH, Buring JE, Willett WC, Krauss RM (1988) Low density lipoprotein subclass patterns and risk of myocardial infarction. JAMA 260: 1917-1921 
4. Austin MA, King MC, Vranizan KM, Krauss RM (1990) Atherogenic lipoprotein phenotype: a proposed genetic marker for coronary heart disease. Circulation 82: 495-506

5. Crouse JR, Parks JS, Schey HM, Kahl FR (1985) Studies of low density lipoprotein molecular weight in human beings with coronary heart disease. J Lipid Res 26: 566-574

6. Tornvall P, Karpe F, Carlson LA, Hamsten A (1991) Relationships of low density lipoprotein subfractions to angiographically defined coronary artery disease in young survivors of myocardial infarction. Atherosclerosis 90: 67-80

7. Campos H, Genest JJ, Blijlevens E et al. (1992) Low density lipoprotein particle size and coronary heart disease. Arterioscler Thromb 12: 187-195

8. Coresh J, Kwiterovich P, Smith HH, Bachorik PS (1993) Association of plasma triglyceride concentration and LDL particle diameter, density and chemical composition with premature coronary artery disease in men and women. $\mathbf{J}$ Lipid Res 34: 1687-1697

9. Griffin BA, Freeman DJ, Tait GW et al. (1994) Role of plasma triglyceride in the regulation of plasma low density lipids to coronary heart disease risk. Atherosclerosis 106: 241-253

10. Watts GF, Mandalia S, Brunt JNH et al. (1993) Independent associations between plasma lipoprotein subfraction levels and the course of coronary artery disease in the St. Thomas' Atherosclerosis Regression Study. Metabolism 42: $1461-1467$

11. Brunzell JD, Albers JJ, Chait A, Grundy SM, Groszek E, McDonald GB (1983) Plasma lipoproteins in familial combined hyperlipidaemia and monogenic familial hypertriglyceridaemia. J Lipid Res 24: 147-155

12. Eisenberg S, Gavish D, Oschry Y, Fainaru M, Deckelbaum RJ (1984) Abnormalities in very low, low and high density lipoproteins in hypertriglyceridaemia. J Clin Invest 74: 470-482

13. Luc G, De Gennes JL, Chapman MJ (1988) Further resolution and composition of the heterogeneity of plasma LDL in human hyperlipoproteinaemia: type III hyperlipoproteinaemia, hypertriglyceridaemia and familial hypercholesterolaemia. Atherosclerosis 71: 143-156

14. McNamara JR, Campos H, Ordovas JM et al. (1987) Effect of gender, age and lipid status on low density lipoprotein subfraction distribution. Results from the Framingham Offspring Study. Arterioscler Thromb 7: 483-490

15. Nikkila M, Solakivi T, Lehtinaki T et al. (1994) Postprandial plasma lipoprotein changes in relation to apolipoprotein E phenotypes and low density lipoprotein size in men with and without coronary artery disease. Atherosclerosis 106: $149-157$

16. Nordestgaard BG, Nielsen LB (1994) Atherosclerosis and arterial influx of lipoproteins. Curr Opin Lipidol 5: 252-257

17. Linden T, Bonjers G, Camejo G et al. (1989) Affinity of LDL to a human arterial proteoglycan among male survivors of myocardial infarction. E J Clin Invest 19: 38-44

18. Anber V, Griffin BA, Packard CJ, Shepherd J (1994) Preferential binding of small, dense LDL to human arterial proteoglycan. Atherosclerosis 109: 217 (Abstract)
19. Hurt-Camejo E, Camejo G, Rosengren B et al. (1990) Differential uptake of proteoglycan-selected subfractions of low density lipoprotein by human macrophages. J Lipid Res 31: 1387-1398

20. Labelle M, Krauss RM (1990) Differences in carbohydrate content of low density lipoproteins associated with low density lipoprotein subclass patterns. J Lipid Res 31: 15771588

21. Chait A, Brazg RL, Tribble D, Krauss RM (1993) Susceptibility of small dense low density lipoproteins to oxidative modification in subjects with the atherogenic lipoprotein phenotype. Am J Med 94: 350-356

22. Betteridge DJ (1994) Diabetic dyslipidaemia. Am J Med 96 [Suppl 6A]: 25S-31S

23. James RW, Pometta D (1990) The distribution profiles of very low density and low density lipoproteins in poorlycontrolled male, type 2 (non-insulin-dependent) diabetic patients. Diabetologia 34: 246-252

24. Barakat HA, Carpenter JW, Milendon VD et al. (1990) Influence of obesity, impaired glucose tolerance and NIDDM on LDL structure and composition. Diabetes 39: 1527-1533

25. Haffner SM, Mykkanen L, Stern MP, Paidi M, Howard BV (1994) Greater effect of diabetes on LDL size in women than in men. Diabetes Care 17: 1164-1171

26. Stewart MW, Laker MF, Dyer RG et al. (1993) Lipoprotein compositional abnormalities and insulin resistance in type 2 diabetic patients with mild hyperlipidaemia. Arterioscler Thromb 13: 1046-1052

27. Tan KCB, Cooper MB, Ling KLE et al. (1995) Fasting and postprandial determinants for the occurrence of small dense LDL species in non insulin dependent diabetic patients with and without hypertriglyceridaemia: the involvement of insulin, insulin prescursor species and insulin resistance. Atherosclerosis 113: 273-287

28. Reaven GM, Chen Y-DI, Jeppesen J, Maheux P, Krauss RM (1993) Insulin resistance and hyperinsulinaemia in individuals with small dense low density lipoprotein particles. J Clin Invest 92: 141-146

29. Selby JV, Austin MA, Newman B et al. (1993) LDL subclass phenotypes and the insulin resistance syndrome in women. Circulation 88: 381-387

30. Haffner SM, Mykkänen L, Robbins D et al. (1995) A preponderance of small dense LDL is associated with specific insulin, proinsulin and the components of the insulin resistance syndrome in non-diabetic subjects. Diabetologia 38: 1328-1336

31. Watson TDG, Caslake MJ, Freeman DJ et al. (1994) Determinants of low density lipoprotein subfraction distribution and concentrations in young normolipidaemic subjects. Arterioscler Thromb 14: 901-910

32. Feingold KR, Grunfeld C, Pang M, Doerrler W, Krauss RM (1992) LDL subclass phenotypes and triglyceride metabolism in non insulin dependent diabetes. Arterioscler Thromb 12: 1496-1502

33. Griffin BA (1995) Low density lipoprotein heterogeneity. In: Betteridge DJ (ed) Dyslipidaemia. Baillières Clin Endocrinol Metab vol 9, no4, Baillière Tindall, London, pp 687-703 